\title{
Government-linked companies' (GLCs) performance - a structuration perspective: Malaysian evidence
}

\begin{abstract}
Malaysian GLCs are under pressure to perform due to their role in helping the country to become a developed nation. Using the structuration theory as a framework, this paper seeks to provide a critical perspective on GLCs' performance. This study has found that GLCs are pressured to strike a balance across political, economic and social goals, and attainment of some of these goals, especially goals non-financial in nature, is not necessarily translated into improved financial performance in the short run. Assessing only the financial aspects of GLCs' performance does not provide a complete picture of GLCs' achievements. Despite the importance of non-financial performance, the challenges associated with defining, measuring and using non-financial indicators remain unresolved. Future research can consider exploring how best to assess the non-financial aspects of GLCs' performance in light of the significance of GLCs' political and social obligations, which do not necessarily lend themselves to financial evaluations.
\end{abstract}

Keyword: Government-linked companies; GLCs; Financial performance; Non-financial performance; Structuration theory; Malaysia 